\title{
Peertechz
}

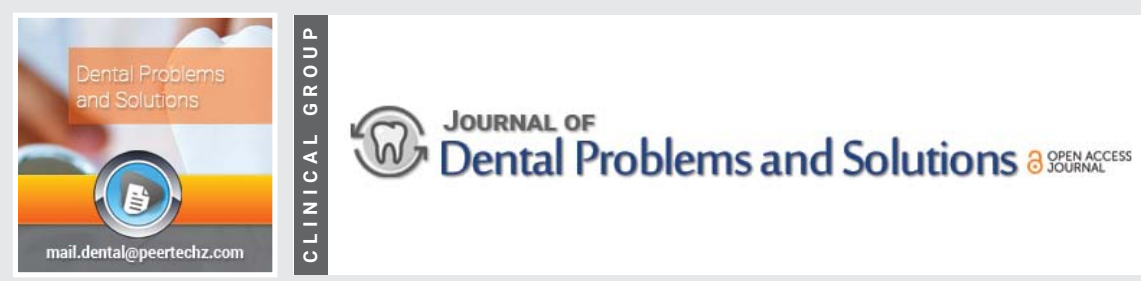

ISSN: $2394-8418$

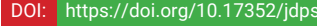

Research Article

\section{The organization of the dental service in the Voronezh region}

\section{Yuri E Antonenkov*}

Associate Professor, Department of Physical and Rehabilitation Medicine, Doctor of Medical Sciences,

Geriatrics of the Institute of Additional Professional Education of the Voronezh State Medical

University named after N. N. Burdenko, Russia

Received: 05 March, 2021

Accepted: 15 March, 2021

Published: 16 March, 2021

*Corresponding author: Yuri E. Antonenkov, Doctor of Medical Sciences, Associate Professor of the Department of Physical and Rehabilitation Medicine, Geriatrics of the Institute of Additional Professional Education of the Voronezh State Medical University named after N. N. Burdenko, Russia E-mail:rhsvjd55@mail.ru

Keywords: Dental service; Curatorship; Perspective directions of development

https://www.peertechzpublications.com

Check for updates

\section{Abstract}

Introduction: The article "Organization of dental services in the Voronezh region» - a large subject of the Russian Federation (RF), the features of the organization of dental care for adults and children are considered.

Materials and methods: Analytical methods and extracts of data from reports of medical organizations of the dental profile of the Voronezh Region for 2017-2019 were used. In accordance with the action plan of the Department of Health of the Voronezh Region, the issues of primary prevention of dental diseases among the population of the Voronezh Region are covered within the framework of the state program of the Russian Federation «Development of Health Care». When considering.

Results: The current state of science and practical health care to preserve the health of the population is reflected, and at the same time, the relevance of dental research remains unchanged. The working dental organizations of the region are described. The analysis of literature sources and reporting materials showed the importance of dynamic observation of medical and social indicators, conditions and lifestyle, the level and structure of dental morbidity, and the demographic situation. The author of the work is well aware of the importance of the background of dental measures aimed at prevention (first of all) and treatment (if necessary). Speaking about the indicators of morbidity in dentistry, the author emphasizes the need to study it to assess the public health of the entire population.

Conclusion: It is emphasized that the priority directions of the development of the dental service of the Voronezh region can be considered (including recommended to other regions): strict implementation of the Program of State Guarantees to the population of the region, equipping dental departments and offices in accordance with the standards of equipment, improving the availability, safety and quality of dental care to the population, as well as the priority of prevention in the field of health protection, including through the school dental service.

\section{Abbreviation}

AUZ: Autonomous Health care Institution; APU: Outpatient Clinic; BUZ: Budget Healthcare Institution; VSU: Voronezh State Medical University; VKSP: Voronezh Clinical Dental Polyclinic; VO: Voronezh Region; VOKSP: Voronezh Regional Clinical Dental Polyclinic; VSP: Voronezh Dental Polyclinic; RB: District Hospitals; RF: Russian Federation

\section{Introduction}

In recent decades, the broadest powers to provide medical care to the population have been transferred to the level of the constituent entities of the Russian Federation, including the dental service. The broad capabilities of specialized medical organizations operating in legally permitted forms of ownership are provided by a significant number of personnel, high external and internal resources, and constant updating of prescriptive directives on professional activities in relation to all personnel with explanations on the implementation of effective and high-quality provision of medical care.

The dental service in the health care system of the Voronezh Region (VO) is currently characterized by the availability and quality of assistance to the population, the introduction of modern dental technologies into practice, and constantly improving the professional level of specialists [1].

\section{Materials and methods}

We used analytical methods and excerpts of these reports (report forms No. 17, 30, 47) of medical organizations of the 
Voronezh Region dental profile to conduct a comparative analysis of the personnel potential of the Voronezh Region dental service in 2017-2019. The availability of information on human resources and the dynamics of medical and demographic indicators over the years under study made it possible to form an opinion that the health of the population is directly related to the results of the preventive work carried out, included in the main indicators of the dental service. In order to analyze and evaluate the results of preventive and curative work to reduce the incidence of diseases among the population in the dental profile, it is extremely important to consider the shortcomings available in the official accounting documents. Therefore, every year the results of the work are summed up through the preparation of an analytical review of the activities of the dental service of the Voronezh Region.

It is this research that makes it possible to form a strategy for organizing work on the part of a dentist working in outpatient clinics (APU) and managing the health care vertical at the regional level.

At the beginning of 2020, in the Voronezh Region, the number of first-time applicants for dental care decreased by $3.9 \%$, and the number of first-time applicants for children decreased by $6.5 \%$.

There is no doubt that the information obtained from the analyzed sources indicates that crisis situations in various spheres of society aggravate social and hygienic factors that affect the dental morbidity in the direction of deterioration. This constantly directs the theoretical and practical parts of the work carried out to re-evaluate the forces of these factors, as well as to find ways to optimize the ongoing preventive work.

This work, carried out in the Voronezh Region, is fully comparable with the existing world experience in planning preventive programs to reduce the dental morbidity of the population, for the strategic unity of science and practice.

\section{Results of the study}

At the beginning of 2020, the dental service of the Voronezh Region, as a subject of the Russian Federation, has 13 dental clinics, including one for children, 19 dental departments, 10 dental offices at district hospitals (RB), 293-at other medical organizations of the Voronezh region, including dispensaries, sanatoriums, general education institutions, enterprises.

The structural composition of dental specialists has remained virtually unchanged in recent years. In 2019, 1156 doctors of dental profile (in state medical organizations) and 607 doctors of non-state dental profile provided outpatient dental care in the region. The share of dentists in the structure of the region's dental specialists working in the public sector was $8.8 \%$ in the reporting year (9.1\% in 2018$)$.

In recent years, the stability of the personnel potential of public sector dental doctors has been noted. In state medical organizations in the region as a whole, in 2019, 1308.5 full time positions of dental doctors were allocated (in 2018 - 1319), employed - 1151 (in 2018 - 1164.25), individuals - 1156 (in 2018-1156). The percentage of staffing for occupied positions was $88 \%$ (in $2018-88.3 \%$ ), for individuals-88.3\% (in 2018 - 87). The percentage of dental doctors in 2019 by position (public sector) is shown in Figure 1.

Of course, the focus is on the work of the therapeutic APUs of the region, both in the adult and in the child population, the figures show the indicators of the availability of dentiststherapists for 2017-2019 (Figures 2,3 respectively).

The priority remains to work with the younger generation on the basis of the principle «prevention is better than treatment» [2]. But with the personnel in the pediatric dentistry of medical organizations of the districts of the region, a difficult situation has developed: the low provision of the children's population with children's dentists (1.7 at the recommended standard of 5.0) due to the insufficient number of full-time positions and their absence in several districts (in 2019, the position of a children's dentist in the Budget Health Institution (BUZ) in the Nizhnedevitskaya RB).

Children's dentists actively participated in the medical examination of the children's population of the region [3]. The

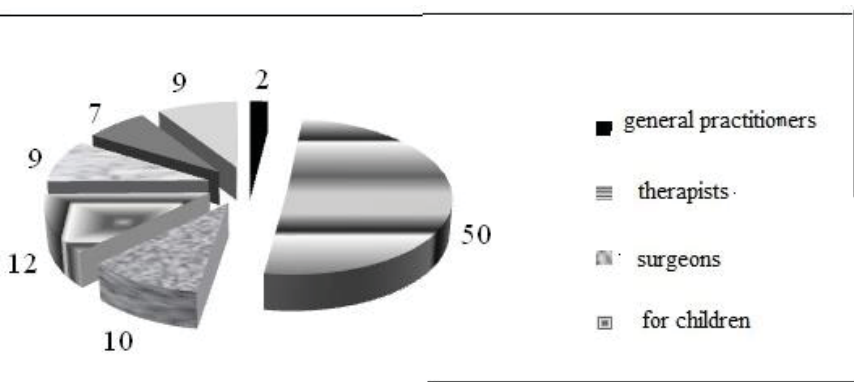

Figure 1: Percentage of dental doctors in 2019 in the Voronezh Region.

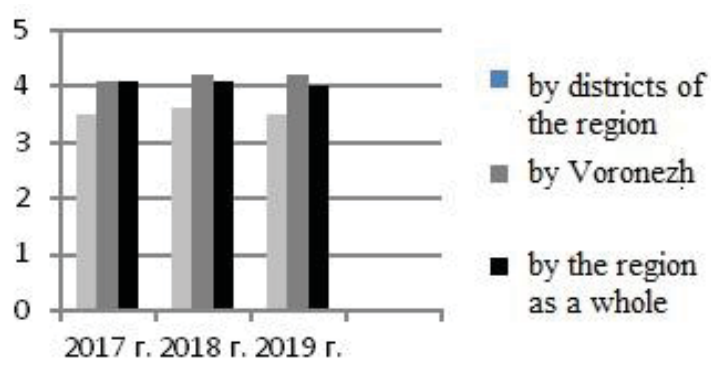

Figure 2: The provision of dentists-therapists per 10 thousand adults in the region in 2017-2019.

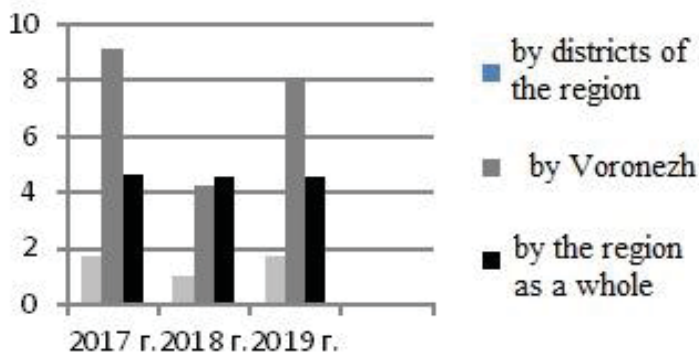

Figure 3: Provision of dentists-therapists for 10 thousand children in the region in 2017-2019 
school preventive program is carried out in all general education institutions of Voronezh and the districts of the region. The activities of the dental service of the Voronezh Region are carried out in accordance with the Procedures for Providing Medical Care to Adults and Children with dental diseases, as well as in accordance with the Clinical Recommendations (treatment protocols) of major dental diseases.

The proportion of sanitized patients from primary referrals in the region in 2019 was $59.85 \%$ (in $2018-60.1 \%$ ), in the regions of the region decreased from $60.5 \%$ in 2018 to $57.62 \%$ in 2019 , in Voronezh increased from $63.1 \%$ in 2018 to $63.4 \%$ in 2019. The indicator of those examined for preventive purposes from the number of primary applicants in the region decreased from $50.1 \%$ in 2018 to $47.36 \%$ in 2019 , in Voronezh also decreased from $46.2 \%$ in 2018 to $45.16 \%$ in 2019 , in the regions of the region there was also a decrease - from $52.4 \%$ in 2018 to $50.04 \%$ in 2019 .

In all schools, gymnasiums and lyceums of Voronezh, hygiene lessons are held in primary school classes on the rules of oral care, and health schools are open. Despite this, the number of people with a healthy oral cavity per 1000 children under the age of 14 years, 11 months and 29 days in the whole region decreased and amounted to 548.73 (in 2018 - 575.42), in the districts of the region the indicator increased slightly - from 477.04 in 2018 to 477.66 in 2019 , and in Voronezh it decreased - from 695.28 in 2018 to 627.13 in 2019 [4].

\section{Discussion}

The implementation of the financial plan for 1 dentistorthopedist for 2019 amounted to $98.5 \%$ in the region (in 2018 $99.4 \%$ ), including $98.5 \%$ in the regions of the region (in 2018 $104 \%$ ), $100.8 \%$ in Voronezh (in 2018-97.6\%). Kantemirovskaya RB (92\%), Repyevskaya RB (93.7\%), Rossoshanskaya RB (91.2\%), Ternovskaya RB (95.97\%), Ertilskaya RB (86\%), VOKB No. 2 (34.3\%), Voronezh Dental Polyclinic (VSP) No. 2 (86.7\%) did not meet this indicator. dental Polyclinic of the Voronezh State Medical University (VSMU) named after N. N. Burdenko (92.6\%), BUZ VO "VSP No. 5" (99.1\%).

Medical organizations of the dental profile of the Voronezh region actively participate in actions carried out within the framework of the regional interdepartmental project «Live long!», with the support of the Department of Health - the program «Kaleidoscope of Health», with the support of the Dental Association of Russia in the person of «Dental Association» from 01.03.2019 to 31.03.2019, the campaign «A dazzling smile for life» was held for schoolchildren of the Voronezh region. And on May 23, 2019, the departure of 3 specialists of the regional clinical dental polyclinic (AUZ VO $\ll$ VOKSP ») was carried out in the city. Liski for participation in the review-competition within the framework of the specified project. This event was attended by representatives of all dental clinics in Voronezh.

In 2019, the specialists of the regional clinical dental polyclinic (AUZ VO «VOKSP») carried out 17 visits to medical organizations in the region (in $2018-17$ ).
Supervision is in AUZ IN «VOKSP» a huge breakthrough in the provision of organizational and methodological assistance to the heads of the dental service areas. In 2019, 1710,438 visits were made to the doctors of the dental profile of the region, which is $2.8 \%$ less than in 2018 (1759,157 visits).

In order to improve dental knowledge in the field and in accordance with the work plan of the dental service of the region, together with the specialized departments of the Burdenko State Medical University, 6 events were held in 2019 (7 in 2018): inter - regional events - 3, regional workshop - 2, city event -1 . Annually, the staff of the regional clinical dental clinic publishes information and methodological materials for dentists of the region. The program of state guarantees for dentistry for 2019, according to preliminary data, was implemented in the region by $101.3 \%$ in the UET, in Voronezhby $100.9 \%$, in the regions of the region-by $100.5 \%$. Below the control values, the PGG was performed by the dental services of the Bogucharskaya RB, Petropavlovsk RB, Podgorenskaya RB, and Ternovskaya RB dental hospitals.

The development and implementation of the main directions of the development of the stomatological service, as well as the coordination of the work of dental medical organizations of all forms of ownership in the region is carried out by the organizational and methodological office of the regional clinical dental polyclinic.

The priority areas of organizational and methodological work are defined as:

* providing organizational, methodological and advisory assistance to the heads of dental services;

* field forms of operational control over the activities of dental units;

* systematic analysis of the activities of the dental service of the region, the implementation of analytical work on the assessment of the state and dynamics of the development of its individual structures;

* development of current and long-term plans for the activities of the dental service of the region, strategic planning;

* organization of activities in priority areas of development of the dental service of the region, their implementation, monitoring and evaluation of the effectiveness of implementation;

* conducting permanent training of specialists of the dental service of the region of the middle and senior level (conferences, seminars);

* information support (issue of methodological recommendations and information letters).

Insufficient provision and understaffing of staff in the districts of the region, especially secondary medical personnel, weak material and technical base of a number of facilities for providing dental care to the population of 
the districts of the region remain problematic [5]. The best performance has reached the dental service of BUZ VO "Anna RB", BUZ VO "Bobrovskaya RB", BUZ VO "Kalacheevskogo RB", BUZ VO "Liskinsky RB", BUZ VO "Pavlovskaya RB", BUZ VO "Ramon RB", BUZ VO "Buturlinovskiy RB", BUZ VO "Novousmanskiy RB". Last rank place in the rating table of the medical organizations of the districts is a dental service BUZ VO "Bogucharskaya RB", BUZ VO "Vorob RB", BUZ VO "Ternovskaya RB", BUZ VO "Kantemirovskaya RB", BUZ VO "Novokhoperskiy RB".

Among the dental clinics in Voronezh, the best indicators were achieved by the VSP No. 6 and VKSP No. 4 dental clinics [5].

\section{Conclusion}

The priority directions of the development of the dental service of the Voronezh Region can be considered, including recommendations to other regions:

* strict implementation of the Program of state guarantees to the population of the region for the provision of dental care;

* equipping dental departments and offices in accordance with the standards of equipping Procedures for providing medical care to adults and children with dental diseases;
* improving the availability, safety and quality of dental care to the population;

* priority of prevention in the field of health protection, including in the organization of the work of the school dental service of the districts of the region;

* entry into the continuing medical education program.

\section{References}

1. Antonenkov Yu, Chaikina NN, Saurina O (2020) About the dental service of the Voronezh Region. Problems of Social Hygiene, Health Care and the History of Medicine. 28: 239-242.

2. Korolenkova M, Khachatryan AG, Harutyunyan L (2020) Perinatal risk factors for caries of temporary teeth. Stomatologiia (Mosk). 99: 47-51. Link: http://bit.ly/3elqOmh

3. Pervushina O, Antonenkov YE, Chaikina N (2014) On the issues of optimizing the work of secondary medical personnel with the adult population in the dentistry of the Voronezh region. Current issues of education and science. 99-100

4. Chubirko M, Chubirko YM, Antonenkov Y (2019) Internal quality control of medical care in scientific publications and regulatory legal acts of the Russian Federation (review). Saratov Scientific and Medical Journal. 15: 928-930.

5. Golikova L, Antonenkov YE, Bortnikova Y (2020) Formation of a healthpreserving environment in youth educational organizations as a basis for the prevention of morbidity. Scientific almanac. 2-2: 76-80.

\footnotetext{
Discover a bigger Impact and Visibility of your article publication with Peertechz Publications

Highlights

* Signatory publisher of ORCID

* Signatory Publisher of DORA (San Francisco Declaration on Research Assessment)

* Articles archived in worlds' renowned service providers such as Portico, CNKI, AGRIS, TDNet, Base (Bielefeld University Library), CrossRef, Scilit, J-Gate etc.

* Journals indexed in ICMJE, SHERPA/ROMEO, Google Scholar etc.

* OAI-PMH (Open Archives Initiative Protocol for Metadata Harvesting)

* Dedicated Editorial Board for every journal

* Accurate and rapid peer-review process

* Increased citations of published articles through promotions

- Reduced timeline for article publication

Submit your articles and experience a new surge in publication services (https://www.peertechz.com/submission).
}

Peertechz journals wishes everlasting success in your every endeavours. 